\title{
The Role of Parents in Their Children's Gender Identity
}

\author{
Guo Chen ${ }^{1, *}$
}

\author{
${ }^{1}$ University of Nottingham, University Park, Nottingham, United Kingdom. \\ Email: gwenchen01@gmail.com
}

\begin{abstract}
In this article, we describe the role that parents in different families may play in the gender identity of their children. Gender identity is a consciousness and an important formative process for children, requiring family education and the influence of social goodwill. It is well known that the family is the first educational environment for children and has a huge influence on their initial identification with the world, including their gender identity. Through in-depth analysis and comparison, this article concludes that different patterns of family formation, the emotional state of parents and their gender identity influence children's attitudes to gender and gender choices. The education from their parents is the basic building block for children to build their gender identity and children need guidance and understanding from their parents.
\end{abstract}

Keywords: role of parents, gender identify, gender education

\section{INTRODUCTION}

Gender is referred to as a social construction, determined by social norms, culture, attitudes, values, traditions, beliefs, and practices. ${ }^{[1]}$ The term "gender identity" was originally coined by Robert J in $1964^{[2]}$. It is a consciousness, an understanding, identification, and acceptance of oneself as a male or female or another non-binary gender. Definition of the Yogyakarta principle says that gender identity is the personal sense of one's gender. ${ }^{[3]}$ Gender identity can correlate with a person's assigned sex at birth or can differ from it. ${ }^{[4]}$ Gender expression typically reflects a person's gender identity, but this is not always the case. ${ }^{[5][6]}$ While a person may express behaviors, attitudes, and appearances consistent with a particular gender role, such expression may not necessarily reflect their gender identity.

\subsection{Parents are the first educators}

Parents are the first people most children come into contact with and spend the most time with. It is through their parents that children acquire their first level of education. Children's brains are like sponges in the first few years of their lives and they absorb everything around them. The education they receive from their parents in the first years of their lives will therefore be a lifelong education for the child, and will influence the choices and thinking of the child for the rest of his or her life. ${ }^{[7]}$ Therefore, one approach is that parents are the first and most important educators of children. From the moment children begin to learn from their parents, this initial education begins to influence them for the rest of their lives and may even be said to have an impact on future social development. It is through family education that children's morals, character, spirituality, cognitive abilities, attitudes and values begin to be shaped in various ways, particularly about issues of gender identity.

In addition, the family also has a role in maintaining harmonious relationships, as the relationships within the family, especially between parents who get along, greatly influence the developmental process of the child. The role of the family, and in particular the fulfilment of the parents' role as role models in the child's life affects the development of the child's character and personality, especially concerning the perception of gender. The role of the family in introducing children to gender identity is therefore very important as a first important step so that children can be properly aware of gender identity and thus be able to develop and optimize their potential appropriately in the future. 


\subsection{Gender identity of children}

Children's gender development can be influenced by genetic factors, but also by family upbringing, social environment, cultural customs, and other factors. Most children develop the ability to categorize others by labeling them according to their gender by the age of 18 to 24 months and use gender labels frequently in their speech (see Martin \& Ruble, 2010). ${ }^{[8]}$ This is where children begin to develop a sense of self and actively seek information about how they should behave (Baldwin \& Moses, 1996). ${ }^{[9]}$ Accordingly, once children at this stage reliably identify and use gender categories, their gender-typed behaviors (e.g. playing with gendertyped toys) increase (Zosuls et al., 2009). ${ }^{[10]}$ Self-gender identification, on the other hand, emerges by the age of 3 years, when children can develop a sense of self-gender identity that is not yet perfect, but is able to correctly state their gender. When they are between the ages of 3 and 4 , children develop the stability of gender identity and they realize that gender does not change over time. Through actions and role models in the home, parents have an impact on shaping their children's gender (Santrock, 2011). ${ }^{[11]}$

\subsection{Research methods}

A combination of Textual analysis and content analysis: A large body of literature on the subject of children's gender education and gender identity was identified and studied in depth. The qualitative analysis and survey data from the literature were used to further analyse the content and to translate textual and pictorial qualitative information into more systematic and accurate information.

Comparative Research Methods: A comparative analysis of three different models of family composition to identify similarities and differences in the influence of children's gender identity.

\section{PARENTS' EMOTIONAL STAT US AND GENDER IDENTITY}

\subsection{Two-parent families}

In a healthy two-parent family relationship, the relationship between the partners is stable and healthy. In this model, the couple's relationship is harmonious and healthy, giving the child a good family environment. As the parents have a good relationship, the child also develops a good feeling and desire for marriage, and the child is more willing to learn and imitate the parents and actively distinguish between the characteristics of the different genders, facilitating the child's initial selflearning about gender. In life, this congenial family atmosphere gives the child fewer sources of stress and they can concentrate more on themselves and their gender awareness exploration. Moreover, the child receives guidance and education from both parents, which gives the child more sound values and the ability to analyze and think independently about social phenomena and their gender perception.

\subsubsection{Heterosexual families}

Heterosexual families are a more common type of family these days. In such a family, the father is typically male and the mother is typically female. The child can learn from both parents a good image of masculinity and femininity, which facilitates the child's understanding of masculinity or femininity; at the same time, both parents are able to give the child a more balanced love and comprehensive family education, which helps the child to construct a sense of self. Sometimes boys are more inclined towards their mothers and girls towards their fathers. For example, in a family model where the husband and wife are closer, the boy may prefers the mother and will subconsciously think: "Why would the mother prefer the father?" He will then follow the father's example in the process of observing, learning and imitating many of the father's strengths, so a good heterosexual family relationship has an impact on the child. And the details of how parents get along in life can enable children to discern the character traits, and differences between different gender roles. However, if heterosexual parents do not understand gender identity, children living in such families may be pressured by their parents to impose traditional gender profiling on them.

\subsubsection{Homosexual families}

Compared to heterosexual parents, homosexual parents are more liberal in their attitudes towards their children's gender-related behavior and they do not deliberately transmit specific gender ideas to their children. Gay parents give more knowledge and ideas about gender identity and are also more open to allowing their children to think independently. This allows children in gay families to feel less pressure from their parents' gender stereotypes and their children to hold more flexible attitudes about gender. In anticipation of future relationships, children from gay and lesbian families are more likely to be less certain that they will experience heterosexual or homosexual relationships in the future. However, this is more related to parental literacy, and there are parents in heterosexual families who know and give their children information about gender identity and are willing to give them the freedom to choose. Henny Bos's study found that children from lesbian families were more likely to be less certain that they would experience heterosexual or homosexual relationships in the future ${ }^{[12]}$, possibly as a result of growing up in a family environment that was more tolerant of homosexual relationships, which is consistent with Tasker and Golombok's (1997) ${ }^{[13]}$ finding that young adults raised by lesbian mothers were more likely 
than those raised by heterosexual parents were more likely to view same-sex relationships as a valid option. Furthermore, uncertainty about future heterosexual relationships does not necessarily mean that children will later identify as lesbian, gay, or bisexual.

\subsection{Families with divorced or unstable couples}

Parents are estranged and often raise their children with one partner. Such a pattern of parenting and education can lead to over-dependence on one of the parents and may result in the child having an overly masculine or overly feminine personality. Parents in such a home environment may neglect to educate their children about gender and rarely provide them with signs of gender categorization such as toys, clothes, hairstyles, toilets, etc. The child may become more confused about gender identity, to the detriment of his or her mental health.

\subsubsection{Father's influence}

Both boys and girls are influenced by their fathers. By the time boys become aware of the gender differences between men and women, they have already begun to imitate their fathers. They often look up to their father as an admirer, observe his every move in life and begin to imitate his hehavior and the way he handles things, the way he speaks, etc. All these details of life influence whether a boy grows up to be a man or not. How a father approaches his family can even determine how a child approaches life in the future. For girls, the role of the father is also very important, and in the girl's initial perception, the father represents almost the entire opposite sex. A girl's perception of her father may influence her attitude towards the opposite sex and affect the way she lives her life.

\subsubsection{The impact of the absence of father in life}

Usually, in a mother-only family or a family dominated by a strong mother, the father is a cold and passive man, and the role he performs in front of his wife makes her look down on him, or the mother is masculine and the family is of the feminine and masculine type, which can disrupt the establishment of the child's idol of identity. If a boy learns his father's process and his mother is very violent and often reprimands her husband, the child is deeply humiliated by his father and fearful of his mother, which can lead him to fear women. For girls, they may be timider, easily frightened, and less active, and at the same time may cause a deficit in their early gender identity, which in severe cases may affect healthy gender development.

\subsection{Non-binary gender families}

Parents in such families are more aware of the importance of gender identity and they will pay more attention to the gender education of their children. These parents usually have more knowledge of gender, so that they will better guide their children and have a more liberal attitude towards their children's gender choices. If the child shows a tendency to have a non-traditional gender identity, they will be better able to guide and educate their child so that their children can have a clearer perception of his or her gender identity. Gender minorities are currently not fully perceived in the minds of society at large, so they may face many social pressures and challenges of cultural differences due to their parents' own gender identity. And this pressure can cause some people from gender minorities to feel anxious, depressed, or even engage in serious self-harm. This situation may also affect their child, who may be subjected to a lack of understanding, bullying, and verbal abuse by others in society, causing mental health problems in the child and thus rejecting the non-binary gender identity.

\section{ANALYSIS OF THE SURVEY SITUATION}

In 2013 Professor Milton Diamond of the University of Sydney conducted a research study on The Views of Transgender Adults on the Needs of Gender-Variant Children and Their Parents.[14] This study explored the childhood experiences of transgender adults. The needs of children that emerged from this process were most evident in the education of parents, school staff and other authority figures, so that children did not need to hide themselves and their gender expressions for fear of adversity. Participants expressed the importance of gender education in childhood. For children to better understand gender identity and accept gender differences, parents must learn about it and educate their children. Otherwise, parents do not have enough knowledge to explain that "gender is not sex" and for children to understand that "gender" is more than just male and female.

They identified this lack of knowledge as a key barrier to their gender development and to parental support, particularly as some participants indicated that their parents were not even aware that transgender people existed. They wanted their parents to love and value their children and provide space for them to talk about their feelings.

Another common need is for parents to provide an unconditionally loving environment with openness and sensitivity where children can talk to their parents about their real feelings and ask questions without any inhibitions. Life for gender variant children is much easier if they are supported to express themselves as 
they naturally feel. One participant said that children need to be "allowed to be themselves and supported to be themselves, rather than being forced into a role that traumatizes them for life" and having to "conform to stereotypes" and being forced to live within the gender framework prescribed by others." Others said that children should be allowed to "explore their gender identity appropriately without fear of bullying" and to "express their true selves to avoid living in pain".

This shows that children's gender identity development requires a great deal of help and guidance from their parents, but at present there are very few parents who can provide this knowledge and guidance, making it difficult for children to receive direct and effective help from their parents when they feel confused about their gender identity. On the contrary, the enormous pressure from parents may cause more serious psychological damage to the child, which may lead to anxiety, becoming depressed or even becoming suicide.

\section{CONCLUSION}

From the above analysis, it can be concluded that parents play a siginificant role in educating their children and introduucing gender identity. The composition of the family, the parents' own views on gender identity , and the parents' education all have an impact on the child's gender identity to some extent. Parental guidance in understanding and learning about gender identity according to the child's characteristics, teaching the child to have a sense of independence, and parental knowledge and attitudes towards sexuality can influence the child's gender development and life experiences. Although there is still much debate and uncertainty about whether parents play a decisive or primary role in their children's gender identity, we can be certain that parents have an important impact in the development of their children's gender identity. What we can say for sure, however, is that parents are the closest people to most children and transmit primary information, and therefore everyone can agree that parents always play an important role in children's development.

Most of the current research focuses on the perception of gender roles in family socialization, gender identity theory, and the social problems and parental attitudes of children of non-binary gender, but few studies have focused on parental education and influence on children before their gender identity is formed. Effective parental involvement and education in the child's gender awareness stage may guide the child's development and may reduce conflict within the family. Effective parental involvement, however, can be difficult to achieve and it is a long and difficult process.

\section{REFERENCES}

[1] Ellyn Sugeng Desyanty, The Role of the Family in Recognizing Gender Identity in Children, 15 December 2020, Advances in Social Science, Education and Humanities Research, volume 508, https://doi.org/10.2991/assehr.k.201214.310

[2] STOLLER, ROBERT J. (November 1964). "The Hermaphroditic Identity of Hermaphrodites". The Journal of Nervous and Mental Disease. 139 (5): 453-457.

[3] Deana F. Morrow and Lori Messinger , Sexual Orientation and Gender Expression in Social Work Practice, (2006, ISBN 0231501862), p. 8: "Gender identity refers to an individual's personal sense of identity as masculine or feminine, or some combination thereof."

[4] Campaign, Human Rights. "Sexual Orientation and Gender Identity Definitions"

[5] Summers, Randal W. (2016). Social Psychology: How Other People Influence Our Thoughts and Actions [2 volumes] ABC-CLIO. p. 232.

[6] American Psychological Association (December 2015). "Guidelines for Psychological Practice With Transgender and Gender Nonconforming People" American Psychologist. 70 (9): 861

[7] Jen Gratz, The Impact of Parents' Background on their Children's Education, Saving Our Nation, Saving Our Schools: Public Education for Public Good Professor Ruthanne Kurth-Schai, Educational Studies 268, November 14, 2006

[8] Martin, C. L., \& Ruble, D. N. (2010). Patterns of gender development. Annual Review of Psychology, 61, 353-381, https://doi.org/10. 1146/annurev.psych.093008.100511

[9] Baldwin, D. A., \& Moses, L. J. (1996). The ontogeny of social information gathering. Child Development, 67, 1915-1939, https://doi.org/ $10.2307 / 1131601$

[10] Zosuls, K. M., Ruble, D. N., Tamis-LeMonda, C. S., Shrout, P. E., Born- stein, M. H., \& Greulich, F. K. (2009). The acquisition of gender labels in infancy: Implications for gender-typed play. Developmental Psychology, 45, 688-701, https://doi.org/10.1037/a0014053

[11] Santrock, J. W. 2011. Perkembangan Anak. Jakarta: Erlangga.

[12] Henny Bos \& Theo G. M. Sandfort , Children's Gender Identity in Lesbian and Heterosexual TwoParent Families , 15 October 2009, Sex Roles (2010) 62:114-126 
[13] Tasker, F. L., \& Golombok, S. (1997). Growing up in a lesbian family. Effects on child development. New York: Guilford.

[14] Elizabeth Anne Riley, Surviving a Gender-Variant Childhood: The Views of Transgender Adults on the Needs of Gender-Variant Children and Their Parents, in: Journal of Sex \& Marital Therapy, Published online: 28 Jan 2013, 39:3,241-263. 